\title{
Distance travelled: Outcomes and evidence in flexible learning options
}

\section{Australian Educational Researcher}

2017

\begin{abstract}
Flexible learning options (FLOs) provide individualised learning pathways for disengaged young people with strong emphasis on inclusivity and wellbeing support. Amidst a rapid expansion of Australia's flexible learning sector, service providers are under increasing pressure to substantiate participant outcomes. This paper stems from a national study of the value of FLOs to young people and the broader Australian community. The study enumerates the outcomes valued by flexible learning practitioners, as well as the various evidence forms they cite to substantiate participant outcomes. Framing success as 'distance travelled' (i.e., an individual's progress relative to his or her own starting point), practitioners demonstrate critical awareness of the social and structural mechanisms by which young people are marginalised from mainstream schooling. Holistic assessment practices also reveal practitioners' efforts to expand the terms of reference by which educational outcomes may be validated in alternative education settings.
\end{abstract}

Keywords: Alternative education; educational outcomes; accountability; evidence; distance travelled.

\section{Authors}

1. Joseph Thomas (Corresponding author)

College of Business, Law and Governance

James Cook University

1 James Cook Drive, Townsville City, QLD, 4811

Email: joseph.thomas1@jcu.edu.au

\section{Professor Sue McGinty}

Australian Aboriginal and Torres Strait Islander Studies Centre

James Cook University

1 James Cook Drive, Townsville City, QLD, 4811

Email: sue.mcginty@jcu.edu.au

3. Professor Kitty te Riele

Deputy Director (Research)

Peter Underwood Centre for Educational Attainment

University of Tasmania, Hobart, Tasmania, 7000

Email: Kitty.TeRiele@utas.edu.au

4. Dr. Kimberley Wilson

Lecturer in Science Education

Australian Catholic University

1100 Nudgee Road, Banyo, QLD, 4014

Email: kimberley.wilson@acu.edu.au 


\section{Introduction}

Someone said to me once, "Are the kids getting a good education?" [...] If you define a 'good education' as going to uni' or finishing Year 12, then no, we're not giving a good education. But if you define 'giving a good education' as giving people the ability to read, write, understand, comprehend, and then giving them opportunities to further themselves, then, yes, we are giving a good education. (Bryan, Waratah)

In the last three decades, neoliberalism has come to dominate education policy discourses internationally, with the value of education increasingly measured against its contributions to national economies (Rizvi and Lingard 2009). Australia is no exception. Schools have been repositioned as competitive firms in the free market (Davies and Bansel 2007), with access to the highest performing schools commodified, stratified and marketed to the discerning consumer (Connell 2013). While proponents of 'school choice' in the Australian context champion the enhancement of educational quality through increased "transparency, accountability and competition" (Grattan 2010 para. 3), opponents warn of the rapid concentration of socioeconomic disadvantage within public sector schools (Lamb 2007; Mills 2015; Vickers 2015) and increasingly inequitable access to high quality education (Gannon 2013; Mills 2015). Disparate access to high quality education in Australia has been exacerbated by recent devolution of enrolment authority (Connell, 2013; Lamb 2007), with school leaders granted considerable discretion to exit low-performing and otherwise 'undesirable' students (Mills et al. 2014; Te Riele 2014). Ironically, mandates to provide alternative pathways for the education and training of disengaged young people (COAG 2009) may actually serve to streamline their exclusion from mainstream schools into FLOs often perceived as "dumping grounds" for problematic students (Kim 2011 p. 78). The burden of such exclusions has been shown to fall disproportionately upon young people with greater needs and, in particular, those from low socioeconomic backgrounds (Mitchell 2016).

In Australia, some 580,000 15-29 year olds are not in employment, education or training (NEET), with substantial social and economic consequences both for these individual young people and the broader community (OECD 2016). Over 81,000 young Australians do not complete upper secondary education ('Year 12') by age 19 (Lamb et al. 2015), significantly increasing their risk of becoming NEET in 
young adulthood. To address the persistent phenomenon of early school leaving, state and nongovernmental organisations across the country have developed programmes to enhance educational access for young people who are experiencing disengagement from mainstream schooling. Broadly identified as Flexible Learning Options (FLOs), these programmes provide alternative educational pathways at junior (Year 7-10) and senior (Year 11-12) secondary levels for disadvantaged young people with strong emphasis on inclusivity and wellbeing support (McGinty and Brader 2005; Te Riele 2007; Mills and McGregor 2014).

While the attendant expansion of FLOs may in many ways represent a critical indictment of the widespread 'marketisation' of Australian education (Connell 2015), these programmes continue to orbit a neoliberal educational system and policy framework to which they are both critique and complement (Vadeboncoeur 2009). With renewed attention among Australia's governing echelons to the equity-informed recommendations of the Review of Funding for Schooling by the (former) Department of Education, Employment and Workplace Relations (see Gonski et al. 2011) and in the light of demands for a stronger evidence base for education policy (Productivity Commission, 2016), advocates of needs-based educational funding are seeking to substantiate the long-term impacts of FLOs (Fox and O'Connell 2016). Yet the appraisal of schooling effectiveness in FLOs is scarcely straightforward, where various combinations of interrupted schooling and economic, social and emotional barriers to positive academic engagement are the norm. Standardised measures for the assessment of student achievement, matriculation and smooth transition to further education, training or employment are thus inadequate in the flexible learning context. To wit, a growing body of scholarship has aimed to elucidate a broad range of personal, social and economic benefits of 'alternative' education for disengaged youth (Evans et al. 2009; Gutherson et al. 2011; Mills and McGregor 2014; Thomson 2014).

In myriad ways, FLO participants are distinctly disadvantaged vis-à-vis the broader student population in Australian schools. Young people usually arrive at FLOs amidst extraordinary challenges and uncertainty in their lives. A range of social and personal circumstances is associated with youth disengagement from secondary education and, by extension, enrolment into FLOs. These complex and interacting factors may include, inter alia: previous educational experiences (e.g., lack of personal and 
learning support, low attendance, interrupted schooling, disciplinary removal); inter-personal factors (e.g., negative peer connections, lack of belonging, carer responsibilities); health and wellbeing status (e.g., disability, trauma, anxiety, depression, disempowerment, substance misuse, negative engagement with police, crime, juvenile incarceration); and other indicators of socioeconomic disadvantage (e.g., poverty, homelessness, Indigenous status, refugee status) (Barrett 2012; Myconos 2012, 2014; EREA 2015).

Flexible learning practitioners define participant achievement in holistic terms, recognising that a young person's future pathways are a function of much more than test scores and high school completion. An examination of 'grey literature' (i.e., practice-based and evaluation reports, often of a single program) by Te Riele et al. (2016) provides a detailed overview of what counts and is valued by participants and practitioners in the flexible learning space. That paper reviewed a range of FLOs' articulated objectives, as well as the evidence types utilised to indicate success in nominated areas. Targeted domains and associated indicators included academic performance (e.g., literacy, numeracy), educational engagement (e.g., attendance, affection with learning), personal and social wellbeing (e.g., mental and emotional health, relationships), post-programme destinations (e.g., transition to further education, training, employment), and community engagement and wellbeing (e.g., social inclusion, participation, youth justice involvement).

With respect to 'engagement,' this concept may be broadly understood as a "'meta' construct" linking various experiential and environmental aspects of schooling (Fredricks et al. 2004 p. 60), comprising behavioural, cognitive and affective subtypes (Christenson et al. 2012 p. 816-817). While engagement is a reflection of a young person's valuing of and participation in learning, it is also a product of structural influences that serve to facilitate or encumber educational access. The re-engagement of disadvantaged young people through FLOs is predicated upon recognition of their marginalisation from mainstream schooling and an explicit institutional commitment to their social and economic reinclusion. This framing of re-engagement connects well with McMahon and Portelli's (2004) conceptualisation of 'critical democratic' engagement, i.e., as "realized in the processes and relationships within which learning for democratic reconstruction transpires" (p. 70). 
The importance of so-called 'soft' (i.e., psychosocial) outcomes is frequently cited in the literature (Brooking et al. 2008; Davies et al. 2011; O'Donovan et al. 2015; Te Riele et al. 2016). Although an increasing number of tools have been made available to educators to facilitate assessment of subjective wellbeing and other 'soft' indicators (Zepke and Leach 2010; Wilson-Ahlstrom et al. 2014), quantitative techniques for meaningful personal and inter-personal comparison remain a matter of theoretical debate (Kristoffersen 2010). While researchers have observed a gradual incorporation of rubrics for the assessment of psychosocial indicators (Evans et al. 2009), their utilisation in FLOs and 'mainstream' schools more generally is both limited and contested. Furthermore, the often 'messy' processes by which young people exit FLOs tend to render post-programme evaluation of outcomes partial or impossible. However, wellbeing assessment at intake is common, with data used in the development of individualised learning plans (ILPs) and provision of support services. In many circumstances, enrolment data and preliminary testing provide baselines against which progress may be assessed at subsequent intervals.

Myconos (2014) and Te Riele et al. (2016), among others, underscore the difficulties FLO practitioners face in the measurement and communication of complex qualitative outcomes, especially given the substantial human and financial resources required to do so. Thomson (2014) suggests that in alternative educational contexts, educators may assess achievement as the extent to which a young person undergoes personal growth through participation in a program. For young people considered 'academically at-risk,' Martin (2013) proposes 'personal best' approaches. In FLOs, the framing of success as 'distance travelled' (Dewson et al. 2000; Evans et al. 2009; Te Riele et al. 2016) (i.e., the progress a young person makes relative to his or her own starting point), is necessarily cognizant of the significant barriers to self-actualisation faced by disadvantaged young people (Davies et al. 2011).

The present study helps to unpack flexible learning practitioners' (implicit and explicit) use of 'distance travelled' as a metaphor to convey the educational outcomes of re-engaged young people. Our analysis is driven by two central questions: 1) What outcomes do practitioners value for young people in FLOs? 2) How do practitioners assess whether or not participants achieve these outcomes? The first question is about purpose; the latter speaks to evidence. 


\section{Methodology}

This paper stems from a larger study of the value of FLOs to young people and the broader Australian community. Eight sites were chosen to represent a cross-section of mature (i.e., operating for more than three years) governmental and non-governmental programmes in four Australian states/territories. Sites were either registered schools or independently governed programmes (i.e., not annexed to mainstream schools). Three of the sites served majority Indigenous cohorts. All of the selected sites offered noncompulsory, credentialed, secondary-level education to previously disengaged young people).

In-depth interviews were recorded with 92 practitioners (i.e., teachers, youth/social workers, support staff and programme administrators) across the eight sites. Our analytical framework comprised a 'hybrid' thematic analysis, involving a balance of inductive and deductive coding approaches (Fereday and Muir-Cochrane 2006). A preliminary, collaborative inductive analysis of interviews and researchers' field observations was first undertaken to identify major themes and outline protocols for the systematic coding of data. QSR International's Nvivo 10 qualitative analysis software was then used to code all interview transcripts in accordance with these protocols. Crosschecks of coded transcripts were undertaken to verify consistency and accuracy of the coding. Transcript excerpts coded with the major theme 'outcomes' were then collated for in-depth analysis of practitioners' views concerning the educational outcomes they value and to elucidate the various evidence forms cited by practitioners to substantiate these outcomes. As respondents' discussion of outcomes frequently overlapped with matters pertaining to student assessment, selection of data was extended to include transcript excerpts coded with the major theme 'measurement.' A third-stage, deductive analysis was then performed, overlaying the superordinate theme (Morrissette 1999; Lewthwaite et al. 2016) 'distance travelled' across the data in order to elucidate various nuanced manifestations of this metaphor in practitioners' responses. To protect the anonymity of respondents and programme participants, the names of young people have been redacted, particular staff titles have not been specified, and all interviewees and their organisations have been ascribed pseudonyms.

The categories of outcomes discussed in the following section correspond closely with findings from other studies of similar programmes (Evans et al. 2009; Mills and McGregor 2014; Te Riele 2014). Our 
investigation is rooted at the programmatic level (i.e., inquiry centres on the educational outcomes of young people to which the various evidence forms cited by practitioners may be directly linked). This delimitation of outcomes is usefully distinguished from the ostensible long-term and macro-level impacts of education. Grounding our analysis at the level of programme participants serves to highlight the educational outcomes most valued by practitioners, as well as the practical means by which these outcomes may be empirically substantiated.

\section{Findings}

Although the focus of this paper is on educational outcomes and the evidence forms used to substantiate them in FLOs, a brief elaboration of the means by which practitioners gather and frame such evidence is relevant. Interviewees indicated broad integration of standardised testing and diagnostic tools, professional judgement, task and course completion, and other forms of achievement benchmarking. The use of formalised wellbeing rubrics was also common to several sites, yet in most cases, data from these tools was principally used to tailor learning and support strategies for individual young people, rather than as evidence of outcomes or to inform whole-of-school improvement processes. Several respondents acknowledged a gap between indications of success commonly cited by practitioners and externally validated evidence forms:

Was seeing a kid that comes in here who's negative, really unhappy—to all of a sudden see a brief smile. To me, that's the start. But that's something that's very hard to measure on a piece of paper. You can't write down, “Oh, so-and-so smiled today.” (Charles, Desert Rose)

Even where supposedly objective benchmarks (e.g., credentials, transition to employment) were held up to indicate achievement, attainments were typically contextualised against the individual and social obstacles faced by disengaged young people. Practitioners overwhelmingly framed notions of 'success' as individual progress, rather than through inter-personal comparison:

You meet them on the first day that they're here. You get painted a picture of them through an assessment and then you see how far they travel within, you know, 10, 20, 30, 40 weeks and 
then, you know, revisiting their learning plan or their pathways plan $[\ldots]$ you'll be able to see the distance travelled. (Tyler, Desert Rose)

Below, findings to the research questions posed (i.e., the outcomes valued by FLO practitioners and the methods by which achievement of these outcomes is assessed) are discussed in relation to five core themes that emerged from the analysis: engagement, wellbeing, literacy and numeracy, certifications and credentials, and post-programme transitional pathways. Discussion of these findings and concluding comments form the final parts of the paper.

\section{Engagement}

Practitioners across all eight sites consistently voiced engagement as an intrinsic and fundamental outcome. Frequent references to attendance indicated a key quantitative metric of participation, as well as a qualitative indication of young people's commitment to the process of change amidst the ongoing circumstances of their disenfranchisement:

Again, first of all if they're coming. Right, that's the first marker. (Brad, Bottle Brush)

We've got a little mantra here that the first thing you should do is you should get them to school. Then you engage them. And then you teach them. (Melissa, Grevillea)

If you've got a kid who hasn't been in school and you get them to being here for $60 \%$ of the time, it's bloody heroic, especially given what else is going on in their lives. It's not as though this is about just getting up and going to school. (Veronica, Blue Gum)

Practitioners tended to endow individual evidence forms with multiple meanings, drawing on a particular form to substantiate a range of outcomes pertaining to engagement. Carissa (Blue Gum), for example, cited attendance and participation in curricular activities as evidence of (behavioural) engagement. Yet she draws on these same indicators to substantiate ameliorated social anxiety (i.e., affective engagement): 
Well one girl $[\ldots]$ was too scared to come into class. [...] I've had to work really hard with her to come up with strategies, like how about you sit near the door so if you get scared, you can leave, and things like that $[\ldots]$. Now the last two and a half weeks, she's just been coming into class, sitting in the classroom, doing her work. Today when we were having our two-hour discussion, she was actually giggling and putting her bit in. I mean this is a different kid than I saw on the first day $[\ldots]$. (Carissa, Blue Gum)

Pointing to the trauma experienced by a young woman, Carissa emphasised her re-engagement as a pathway to personal transformation. Practitioners also uncovered evidence forms highly particular to their cohorts. Veronica (Blue Gum), for example, cited Children's Court decisions as externally validated evidence of engagement (with the ancillary benefit of better legal outcomes):

I know that sounds ridiculous, but [...] what we find is that the kids have got better outcomes from court because they can demonstrate that they are in a programme that is productive for them and that they are attending. [...] So I think the magistrates feel like they don't have to apply other sanctions because there's something that actually is happening that is constructive for the young person. (Veronica, Blue Gum)

This reference to legal proceedings served to situate the role of the FLO within the broader context of socioeconomic disadvantage. Yet by qualifying improved court outcomes as sounding "ridiculous," Veronica tacitly acknowledged her limited agency as a grassroots-level practitioner to declare and validate such broadly conceived impacts of education.

\section{Wellbeing}

In the flexible learning context, wellbeing is a broad and holistic notion encompassing physical, mental and emotional health, and includes aspects of personal and collective empowerment deriving from young people's self-regard, satisfaction, resilience, regulation, locus of control, sense of belonging, relationships, and access to resources and opportunity. 
It's really evident that people's ability to form attachments, form meaningful supportive relationships is really compromised. So having a place where they feel safe, where they can form those attachments and then if there's any scope for some sort of visioning or skill development $[\ldots]$. But underneath, first and foremost, is that place of safety and that capacity to be able to form an attachment. I think that then enables all of the other possibilities that happen after that. (Molly, Desert Rose)

While Molly was clear that she wanted young people to exit the FLO with educational credentials, this desire was qualified with reference to engagement that engenders a positive sense of belonging and enables young people to value themselves. Her characterisation suggested that this cohort of young people face pervasive insecurity, which compromises positive engagement in various life domains. Molly thereby depicted wellbeing (i.e., affective engagement) both as a requisite and catalyst of meaningful engagement with learning, as well as a valuable outcome in its own right. Similarly, Brad (Bottle Brush) drew on a young person's improved self-regulation and inter-personal communication as evidence of empowerment. He explained that the young person "comes from a history of severe trauma" and initially displayed "extreme disruption." Over time, Brad recalls, "there's been improvement out of this world in terms of his behaviour and just his level of respect." Such improvements do not simply reflect social niceties; they comprise evidence of affective and behavioural engagement.

While the value of independence and positive self-concept was embedded across all sites, explicit reference to positive communal identity was reiterated in particular at sites with significant Indigenous cohorts:

So going from more basic strength to a little bit more and stretching out their confidence, but also making them feel that their identity and their culture is of value - it doesn't need to be measured against something to be considered good or bad. (Ryan, Desert Rose) 
I've talked to a few people that've come from Sydney and Melbourne and [...] they've got this very bad image and negative thing about Aboriginal people - that they're useless and they're very not really bright and they can't read and write and they can't really achieve anything in life. A lot of young people believe that's the way they are, which is really sad. One of my goals here is to change that. (Wade, Sturt Pea)

Shirley (Sturt Pea) tied an Indigenous young person's wellbeing directly to his social integration. His distance travelled, evidenced by improved personal agency, self-regulation and employability, signalled a novel leadership capacity and the potential to enhance the wellbeing of others in his community:

[The young person] was in some sort of traumatic space [...] people thought he was dumb. [...] He had about a year and a half with one really good teacher at primary school that he talks about, then he didn't go to school [...]. Then he came to us. We tackled all sorts of stuff [like], 'How do we have a shower?' Get all the stuff, like, 'This is a toothbrush, this is toothpaste' $[\ldots]$, do excursions to get haircuts $[\ldots]$. And then slowly-over like two, three years - he was transformed. [...] He started getting physically active; he's lost lots of weight. Look at his dress now [...]. Without a doubt [...], if this wasn't here, [he] would be unemployable - in a space where he probably wouldn't even leave the house. Now he is going to make a difference in his world and the world around him. He's like a leader in his community... Amazing. (Shirley, Sturt Pea)

Shirley appeared to reference employability not as an end unto itself, but as a marker of the young person's acquired agency to affect his own social integration. Lucy (Blue Gum) reiterated that integration is also about structural access (in this case, to information and services). Improved wellbeing was thus evidenced by the provision of information to support present and future mental health outcomes:

From a mental health support side of things, I think a lot of them have struggled $[\ldots]$ with different aspects of their life. I think that they come out with very good support networks for 
their mental health. Not only through here but they know how to access the stuff outside. We've done a lot of information sessions for the young people this year too, you know, around that 'life' stuff. (Lucy, Blue Gum)

Practitioners frequently 'layered' evidence forms in order to substantiate outcomes in light of a young person's distance travelled, and to triangulate the role of the wellbeing support offered by the FLO in this transformative process. As evidence of personal empowerment, Wendy (Blue Gum) cited a young woman's programme participation, self-regulation and substance misuse rehabilitation:

One girl in particular has had really a hard time. Really, really hard. There was domestic violence and there was mental health issues and things like that within her family. [...] When I met her in this program, she was very, very angry—very angry. Most of the time she would storm out of class. She had a lot of anxiety and she had a lot of low self-esteem again and just not able to cope. No coping mechanisms. Through just little bit by little bit by little bit, I've seen her change and grow. [...] I think it's through the support in this program. She's got a supportive teacher. She's got a supportive [youth] worker like person in the classroom. If she's struggling, there's someone there to go, "Can you help me with this?" She's got the support team within the wellbeing office. They've linked her into several different things. She's actually just recently gone through a detox programme and come out the other side quite successfully. (Wendy, Blue Gum)

Considered individually, each of these evidence forms (participation, self-regulation and rehabilitation) comprises a worthwhile psychosocial outcome. Presented together, however, Wendy has woven a more holistic narrative in which the FLO played a central role in a young person's recovery and reengagement.

These findings highlight that wellbeing was related to both affective engagement (e.g., self-regard) and behavioural engagement (e.g., personal hygiene). Furthermore, these forms of engagement were conceived as valuable in their own right, as well as enabling of other outcomes, including more 
'traditional' notions of academic success such as literacy and numeracy, certifications and credentials, and the development of post-programme transitional pathways.

\section{Literacy and numeracy}

With reference to 'traditional' academic outcomes and other indications of cognitive engagement, practitioners frequently reiterated the importance of 'functional' literacy and numeracy-i.e., the level required for the daily tasks of living as adults in a complex, modern society. Far from simplistic notions of remedial instruction, respondents tied acquisition of basic literacy and numeracy skills directly to improved independence and opportunities:

I would hope that young people who come to Bottle Brush and engage with us leave with higher levels of literacy than they came with, and that when they do make the choice to leave, it's because they're ready to move on to something else and that they can function in the community. So they can read and they can make sure that they're not being ripped off, and they can check that their Centrelink payments are right—as an absolute minimum, that they're functional. (Alexis, Bottle Brush)

Notwithstanding the perceived need for external validation of these outcomes (e.g., through certification), literacy and numeracy were never severed from their psychosocial corollaries. Basic academic competencies were seen as tightly intertwined with the self-realisation, wellbeing and social integration of young people. Brooke (Waratah) linked literacy to individual and community empowerment, enabled by the interruption of intergenerational educational disadvantage:

Especially in the [suburb] area where most of our students are coming from-it's low socioeconomic and has a history of drugs and alcohol. We want to change that image. We've had a lot of good feedback from the parents, parents who came to us and say, "Thank you." Parents who couldn't read and write and now their kids can read and write. So that's something in terms of changing or breaking the cycle of illiteracy. (Brooke, Waratah) 
Throughout the interviews, the value of schooling was explicitly situated in light of community disadvantage. Practitioners framed literacy and numeracy not only as means of self-realisation, but also as requisites of social equity. This characterisation was repeatedly extended to the value of certifications and credentials.

\section{Certifications and credentials}

Practitioners stressed that the majority of FLO participants were keen to complete school, if initially unsure about their future plans. Discussion of certifications provided several illustrative examples of how practitioners ascribed multiple meanings to the outcomes and evidence forms used to substantiate impact. Caroline (Waratah) pointed to a young woman's Year 12 certification and work experience to emphasise her improved physical health, behavioural and cognitive engagement and inter-personal development:

She was 14 years old. [...] She had a mum who was I think in prison, a little brother who was going into prison $[\ldots]$. This young woman was a heroin user, but she was trying to get into a local high school. They wouldn't accept her because she was a disengaged student and she wasn't attending enough. She came to us and she started attending regularly. [...] She was very bright and she started engaging well in the school work with her teacher and over time [...] was able to get on top of her drug use through referral to services that we provided her with $[\ldots]$. But we also provided her with on-site $[\ldots]$ counselling regularly and assisted her with managing difficult relationships with her boyfriend at the time, with her mum in jail with her little brother who she was worried about $[\ldots]$. We got her into like a TAFE course where she continued on with Year 12 with us. But she was out in the community doing like [...] some sort of health certificate. So she completed that whilst with us and then she got some work experience at a local hospital. By the time she finished with us, she had her Year 12. (Caroline, Waratah)

Although practitioners frequently referenced certification and graduation as signals of inter-personal growth and resilience, they also readily identified the basic economic functionalism of certifications. 
Carissa cited course completion as a requisite of employment, but also underscored the role of employment in breaking the "cycle of poverty," a social construct:

I want these kids to get an education first and foremost. I want them to be able to pass a Year 10 and a Year 11 and Year 12 because, unfortunately, our society operates in a way that you need that certificate to get certain jobs. [...] When you ring employers, you know, they don't care; they just want to take the kids that got the Year 12 pass. [...] If we're going to break that cycle of poverty and help these kids to get jobs, they need to have that piece of paper. (Carissa, Blue Gum)

Carissa thereby positioned course completion, even through its symbolic attributes (e.g., signalling effects), as a means to enact social inclusion. Like literacy and numeracy, practitioners consistently embedded the individual value of certification and credentials within broader notions of social transformation:

To actually break that cycle you need to get a good education, because the reality is that you need money to survive and to do things. And so I guess here they have $[\ldots]$ the opportunity to work on the issues that have probably run through their family for generations - whether it's abuse or poverty, we're here to help them work through finding a good job, or even a job, that just helps them get by. If there's been trauma, help them and work on that $[\ldots]$ and then I guess we all pray that when they have a family they don't go on to repeat what their parents have done. (Brad, Bottle Brush)

Post-programme transitional pathways

Finally, practitioners were also deeply committed to building positive, post-programme transitional pathways for young people. Successful pathways were indicated by certification, employability, and transition into further education, training and employment, but were necessarily attended by enhanced wellbeing, visioning and novel hope for the future: 
I think sometimes [young people] come in and they figure, "You know, I'll go and get a job one day and I'll make enough money to live," but they don't really envision this happy, content future where they're comfortable or anything like that. [...] Sometimes they walk away afterwards sort of thinking, you know, maybe the future that they've envisioned down the pathway has changed a little bit, maybe it's a bit brighter. There's more possibility. (Trina, Acacia)

By framing young people's intention to succeed as acquired agency over transitional outcomes, Trina leveraged evidence of affective engagement (i.e., dispositional optimism) as an indication of durable programme impact. Jacob (Wattle) draws on a young person's attendance and successful transition, characterised as a personal journey of recovery, to validate the FLO's prioritisation of young people's sense of belonging and connection:

Imagine the worst things that could happen to young people; they all happened to him within those two years and he didn't want to be at school. [...] But through the connection pastorally with staff, he pulled himself back into the school, re-engaged with his learning. [...] We've got staff whose job it is to drive to his house and check on him and to talk to his family. Those things, I think, keep him connected and we got him back in. Now he's going to be a teacher. We're very proud. I think of the future that he can have and who he is now. (Jacob, Wattle)

Thus, pastoral care was seen as essential to root young people within a community of learning, enabling novel possibilities for the future. Jacob and other practitioners consistently emphasised the facilitating role of the FLO in this process.

\section{Discussion}

Practitioners interviewed for this study consistently extolled the value of 'traditional' academic outcomes, including functional literacy and numeracy, certifications and credentials, and pathways for transition into further education, training and employment. Yet they were keen that assessment of their professional outcomes not be constrained to these readily quantified criteria. In their view, educational 
success is also predicated on ensuring the critical engagement and enhanced wellbeing of young people. Practitioners repeatedly underscored the importance of education as a means to strengthen participants' sense of personal agency and enact social transformation.

To substantiate such outcomes, practitioners drew on a range of evidence forms that extended well beyond standardised testing and course completion. Although they reported use of quantitative assessment methods, practitioners also related a strong reliance on their professional judgement and relationships of care to assess outcomes in qualitative terms. Alongside a number of externally validated indicators, outcomes were evidenced through improved attendance, participation, selfregulation, independence, health, security, self-concept, attachment, belonging, inter-personal communication, critical thinking and access to information and resources.

These individual evidence forms were often ascribed multiple meanings to substantiate various manifestations of educational re-engagement. For example, in the context of newly re-engaged young people long absent from formal schooling, attendance simultaneously signified behavioural engagement and enhanced personal agency. For a young woman with severe social anxiety, class participation demonstrated both burgeoning cognitive engagement and enhanced inter-personal communication. A young man's graduation certificate was used to indicate successful course completion, but also his transformed sense of personal security and social belonging.

In the FLOs of this study, outcomes were rarely assessed with reference to normed standards or cohortderived benchmarks. That is, recognition of young people's accomplishments was not reduced to 'objective' indicators (e.g., reading scores or certification levels) and was never based on inter-personal comparison or competition with peers (see also Waters 2016). Young people were not ranked by FLO practitioners. On the contrary, outcomes were in nearly all cases appraised as the personal progress made relative to each young person's unique starting point. Even standardised assessment and credentialing were generally framed through the lens of 'distance travelled' and in light of the experiences and circumstances that led to the young person's initial disengagement. Nor were accomplishments organised hierarchically by relative magnitude or perceived importance. A Year 12 completion was not framed as inherently more valuable than a vocational certificate in hospitality. 
High reading scores on a standardised test were not seen as fundamentally more important than the choice to attend the FLO on any particular morning. Personal accomplishments were recognised in whatever form they appeared and celebrated as significant irrespective of the attainments of others.

Assessment of outcomes in the flexible learning arena is often characterised by a lack of "clear and convincing evidence" (Te Riele et al. 2016, p. 10). It is not surprising that the multiple meanings and cross-applications of evidence forms seen here do not feature prominently in the organisational reports and external professional assessments of many FLOs. In isolation, these accounts' exude an apparent lack of consistency at odds with the standardised assessment regimes privileged in the Australian (and international) educational policy sphere. Yet taken together, the myriad evidence forms compiled in the present study comprise a rich and substantive basis for the appraisal of outcomes. The gathering of such evidence requires significant time and professional resources and was, in all cases, grounded upon practitioners' deep understanding of the young people with whom they work.

While acknowledging the professional, financial, temporal and methodological barriers to formal, systematic evaluation in the flexible learning context (Thomson 2014), it is important to note that the practitioners interviewed for this study were not only interested in evaluation, they were perpetually engaged in it. Flexible learning practice and pedagogy, particularly with regard to ILPs, are fundamentally informed by the individual needs of participants. ILPs are continually reassessed and adjusted to reflect each learner's progress, interests, motivations and capabilities. As these are in constant fluctuation, the evaluation process must be undertaken in perpetuity. In staff meetings, professional development sessions, 'morning circles' and nearly every interaction with young people in classrooms and out in the community, practitioners interrogate the efficacy of their own methods. Often with little formal documentation to show for it (let alone sufficient organisational capacities to collate and present such documentation) (Myconos 2011), practitioners make evidence-informed adjustments to pedagogy and practice with the concerted input of educators, school administrators, youth and social workers, support staff, vocational training providers, family members, community stakeholders, and representatives of public service sectors, including youth justice and welfare support. 
For all the emphasis on "evidence-based policy and professional practice," in a public sphere ever more obsessed with measurement and cross-validation (Rizvi and Lingard 2009, p. 49), the evidence provided by flexible learning practitioners is too often and too easily dismissed as 'anecdotal.' The present analysis offers an alternative perspective. Although collection of data was rarely standardised, practitioners readily acknowledged the impetus for the validation of their outcomes. They drew on the vernacular of educational policy discourse to communicate empirical progress towards declared ends. Such assessment processes can hardly be considered ad-hoc; they are cognizant, continuous and critical.

\section{Conclusion}

It is disappointing, to say the least, that the whole discussion about evidence-based practice is focused on technical questions - questions about 'what works' — while forgetting the need for critical inquiry into normative and political questions about what is educationally desirable. (Biesta 2007, p. 21)

This paper illuminates flexible learning practitioners' validation of educational outcomes on their own terms. Practitioners were shown to push the boundaries of the prevailing assessment paradigm to assert their own perceptions of the underlying purpose and value of education. By endowing the evidence forms used to substantiate outcomes with multiple meanings, practitioners advocated that engagement and wellbeing are inextricably linked to literacy, matriculation and other 'traditional' academic outcomes. Although such linkages are not necessarily linear or causal, the outcomes valued by flexible learning practitioners appear inherently co-dependent and multi-indicative.

Flexible learning practitioners spoke frequently about "breaking the cycle" of educational disadvantage and socioeconomic disenfranchisement. For them, the re-engagement of young people was a practice of social justice, a transformative process whereby individuals and communities may overcome their institutionalised exclusion (see also Mills et al. 2015). Supporting FLOs as agents of social transformation requires recognising, validating and strengthening the means by which practitioners assess and communicate the outcomes that enable such change. 
Practitioners also recognised the economic functionalism of education. Yet they challenged the means by which this may be actualised given the disenfranchisement of disengaged young people. By framing educational outcomes through the lens of 'distance travelled,' practitioners contextualised the gap between promise and practice, broadening the discussion of educational outcomes to include a critical consideration of socioeconomic exclusion. Young people in FLOs regularly demonstrate the resilience demanded within an increasingly insecure, globalised economy. Yet to produce evidence of these capacities requires 'real-world' testing — for a young person to be faced with uncertainty, to be made to feel insecure. It is the privilege of the enfranchised that such trials are not defining characteristics of their youth and education. For disenfranchised young people, the demonstration of new abilities to confront and overcome manifest barriers to their social and economic integration comprises (perhaps the most) significant evidence of the impact of FLOs.

\section{Acknowledgements}

Research for this paper was supported by the Australian Research Council (ARC) Linkage Projects funding scheme for the project, Gauging the value of flexible learning options for disenfranchised youth and the Australian community (LP130100344). The ARC has had no involvement in the study design; collection, analysis and interpretation of data; writing of the report; or the decision to submit this article for publication.

\section{References}

Barrett, A. (2012). Building relationships for better outcomes - Peninsula Youth Connections evaluation Stage 2 report. Fitzroy: Brotherhood of St. Laurence. Retrieved from http://www.bsl.org.au/

fileadmin/user_upload/files/research/reports/Barrett_Building_relationships_for_better_outco mes_PYC_Stage_2_evaluation_report_2012.pdf. Accessed 21 June 2017.

Biesta, G. (2007). Why "what works" won't work: Evidence- based practice and the democratic deficit in educational research. Educational theory, 57(1), 1-22.

Brooking, K., Gardiner, B., \& Calvert, S. (2008). Background of students in alternative education: Interviews with a selected 2008 cohort. Report prepared for the Ministry of Education: New Zealand Council for Educational Research. Retrieved from http://www.nzcer.org.nz/research/ publications/background-students-alternative-education-interviews-selected-2008-cohort.

Christenson, S., Reschly, A., \& Wylie, C. (2012). Epilogue. In S. Christenson, A. Reschly, \& C. Wylie (Eds.), Handbook of research on student engagement. New York: Springer Science \& Business Media.

Connell, R. (2013). The neoliberal cascade and education: an essay on the market agenda and its consequences. Critical Studies in Education, 54(2), 99-112.

Connell, R. (2015). Markets All Around: Defending Education in a Neoliberal Time. In H. Proctor, P. Brownlee, \& P. Freebody (Eds.), Controversies in Education: Orthodoxy and Heresy in Policy and Practice (pp. 181-197). London: Springer.

Council of Australian Governments (COAG). (2009). National partnership agreement on youth attainment and transitions. Canberra: AGPS

Davies, B., \& Bansel, P. (2007). Neoliberalism and education. International Journal of Qualitative Studies in Education, 20(3), 247-259. 
Davies, M., Lamb, S., \& Doecke, E. (2011). Strategic review of effective re-engagement models for disengaged learners. Melbourne: Centre for Research on Education Systems-University of Melbourne.

Dewson, S., Eccles, J., Tackey, N., \& Jackson, A. (2000). Measuring soft outcomes and distance travelled: a review of current practice. London: Department for Education and Employment.

Edmund Rice Education Australia (EREA), Youth+. (2015). Young person profiling tool. Unpublished internal document.

Evans, J., Meyer, D., Pinney, A., \& Robinson, B. (2009). Second chances: Reengaging young people in education and training. Essex: Barnardos.

Fereday, J., \& Muir-Cochrane, E. (2006). Demonstrating rigor using thematic analysis: A hybrid approach of inductive and deductive coding and theme development. International journal of qualitative methods, 5(1), 80-92.

Fredricks, J., Blumenfeld, P., \& Paris, A. (2004). School engagement: Potential of the concept, state of the evidence. Review of educational research, 74(1), 59-109.

Fox, S. \& O'Connell, M. (2016) 'If not Gonski funding, then what?' The Conversation. 6 April, viewed 8 April, 2016. Retrieved online from http:// https://theconversation.com/if-not-gonskifunding-then-what-57

Gannon, S. (2013). My school redux: re-storying schooling with the My School website. Discourse: Studies in the cultural politics of education, 34(1), 17-30

Gonski, D., Boston, K., Greiner, K., Lawrence, C., Scales, B., \& Tannock, P. (2011). Review of Funding for Schooling-Final Report. Canberra: Department of Education, Employment and Workplace Relations (DEEWR).

Grattan, M. (2010, January 29, 2010). My School criticism fails test, Political Opinion. The Sydney Morning Herald. Retrieved from http://www.smh.com.au/federal-politics/politicalopinion/my-school-criticism-fails-test-20100128-n1rm.html

Gutherson, P., Davies, H., \& Daszkiewicz, T. (2011). Achieving successful outcomes through Alternative Education Provision: an international literature review. Reading: CfBT Education Trust.

Kim, J. (2011). Narrative inquiry into (re) imagining alternative schools: A case study of Kevin Gonzales. International Journal of Qualitative Studies in Education, 24(1), 77-96.

Kristoffersen, I. (2010). The metrics of subjective wellbeing: Cardinality, neutrality and additivity. Economic Record, 86(272), 98-123.

Lamb, S. (2007). School Reform and Inequality in Urban Australia. In R. Teese, S. Lamb, M. DuruBellat, \& S. Helme (Eds.), International studies in educational inequality, theory and policy (pp. 672-709). Dordrecht: Springer.

Lamb, S., Jackson, J., Walstab, A., \& Huo, S. (2015). Educational opportunity in Australia 2015: Who succeeds and who misses out, Centre for International Research on Education Systems, Victoria University, for the Mitchell Institute. Melbourne: Mitchell Institute.

Lewthwaite, B., Wilson, K., Wallace, V., McGinty, S., \& Swain, L. (2016). Challenging normative assumptions regarding disengaged youth: a phenomenological perspective. International Journal of Qualitative Studies in Education, 1-18. doi:10.1080/09518398.2016.1252867.

Martin, A. (2013). Improving the achievement, motivation, and engagement of students with ADHD: The role of personal best goals and other growth-based approaches. Australian Journal of Guidance and Counselling, 23(01), 143-155.

McGinty, S., \& Brader, A. (2005). Educational disengagement: A review of international, Australian and state policy responses. In A. Pandian, M. Kabilan, \& S. Kaur (Eds.), Teachers' practices and supportive cultures (pp. 25-35). Serdang: Universiti Putra Malaysia Press.

McMahon, B., \& Portelli, J. P. (2004). Engagement for what? Beyond popular discourses of student engagement. Leadership and Policy in Schools, 3(1), 59-76.

Mills, C. (2015). Implications of the My School website for disadvantaged communities: A Bourdieuian analysis. Educational Philosophy and Theory, 47(2), 146-158.

Mills, M., \& McGregor, G. (2014). Re-engaging young people in education: Learning from alternative schools. London: Routledge.

Mills, M., McGregor, G., Hayes, D., \& Te Riele, K. (2015). 'Schools are for us': The importance of distribution recognition and representation to creating socially just schools. In K. Trimmer, A. Black, \& S. Riddle (Eds.), Mainstreams, Margins and the Spaces In-between: New Possibilities for Education Research (Vol. 130, pp. 150-167). Oxon: Routledge.

Mitchell, J. (2016). Out of sight, out of mind? The exclusion of students from Victorian schools - A preliminary discussion paper. Melbourne: Youth Affairs Council of Victoria. 
Morrissette, P. (1999). Phenomenological data analysis: A proposed model for counsellors. Guidance \& Counseling, 15(1), 2-7.

Myconos, G. (2011). A Path to Re-engagement: Evaluating the First Year of a Community VCAL Education Program for Young People. Fitzroy: Brotherhood of St. Laurence.

Myconos, G. (2012). Re-engagement, training and beyond. Evaluating the second year of a Community VCAL education program for young people. Fitzroy: Brotherhood of St. Laurence.

Myconos, G. (2014). Lessons from a flexible learning program. The Brotherhood of St Laurence Community VCAL education program for young people 2010 - 2013. Fitzroy: Brotherhood of St. Laurence.

NVivo qualitative data analysis software. QSR International Pty Ltd: Windows Version 10.

O'Donovan, R., Berman, N., \& Wierenga, A. (2015). How schools can move beyond exclusion. International Journal of Inclusive Education, 19(6), 645-658.

OECD. (2016). Investing in Youth: Australia. Paris: OECD Publishing. Retrieved from http://www.oecd.org/australia/investing-in-youth-australia-9789264257498-en.htm.

Productivity Commission (2016). National Education Evidence Base, Draft Report, Canberra

Rizvi, F., \& Lingard, B. (2009). Globalizing education policy: Oxon: Routledge.

Te Riele, K. (2007). Educational alternatives for marginalised youth. The Australian Educational Researcher, 34(3), 53-68.

Te Riele, K. (2014). Putting the jigsaw together: flexible learning programs in Australia. Melbourne: The Victoria Institute for Education, Diversity and Lifelong Learning.

Te Riele, K., Wilson, K., Wallace, V., McGinty, S., \& Lewthwaite, B. (2016). Outcomes from Flexible Learning Options for disenfranchised youth: what counts? International Journal of Inclusive Education, 1-14. doi:10.1080/13603116.2016.1168878.

Thomson, P. (2014). Literature Review - What's the Alternative? Effective Support for Young People Disengaging from the Mainstream. Nottingham: The Prince's Trust.

Vadeboncoeur, J. (2009). Spaces of difference: The contradictions of alternative educational programs. Educational Studies, 45(3), 280-299.

Vickers, M. (2015). Neglecting the evidence: Are we expecting too much from quality teaching? In H. Proctor, P. Brownlee, \& P. Freebody (Eds.), Controversies in Education: Orthodoxy and Heresy in Policy and Practice (pp. 81-90). London: Springer.

Waters, R. (2016). Symbolic non-violence in the work of teachers in alternative education settings. Teaching Education, 1-14. doi:10.1080/10476210.2016.1210593.

Wilson-Ahlstrom, A., Yohalem, N., DuBois, D., Ji, P., Hillaker, B., \& Weikart, D. (2014). From soft skills to hard data: Measuring youth program outcomes. Washington, DC: Forum for Youth Investment.

Zepke, N., \& Leach, L. (2010). Beyond hard outcomes: 'soft' outcomes and engagement as student success. Teaching in Higher Education, 15(6), 661-673. 